\title{
Diesel powered vehicle share and transport fuel demand, an aggregate approach applied to Spain.
}

\author{
Alessandro Danesin
}

June 1, 2011

\begin{abstract}
The increasing mobility and the associated fuel consumption has tremendous effects on the environment. Regarding Greenhouse Gases, the recent commitment for reduction can not leave unaffected this crucial sector. For that, a deep analysis of how socio-economic factors move the demand for fuel is needed. One of the main obstacles in this aggregate analysis of this demand has been the shift, in Spain as in large part of Europe, from gasoline-powered to diesel-powered vehicles. In this paper an econometric analysis of how this shift can affect both gasoline and diesel consumption pattern is provided, by applying 5 different estimators to a modified habit-persistence model. Data come from a panel composed by the peninsular autonomous communities in Spain. Results show a high impact of the share of diesel powered vehicles when considering the specific gasoline and gasoil demand but the same does not hold when considering the total fuel consumption, where the impact is much lower.
\end{abstract}




\section{Introduction}

The demand for transportation and the related energy demand has been in recent years at the center of a large academic and public policy debate. This is basically due to the fact that the increasing private travel demand, in large part generated by cars, has resulted in a significant growth in oil demand. This increasing oil demand has its impact on both the dependence from foreign energy sources (common in most developed countries) and on global pollutants, mostly $\mathrm{CO}_{2}$. These two issues appear to be on the top of many governments' agendas, suggesting how lively and current is this discussion. In 2007, according to the European Energy Commission report (European Commision, 2010), road transportation was responsible for $20.12 \%$ of total $\mathrm{CO}_{2}$ emissions in Europe, increasing from 704.3 million tonnes in 1990 to 905.0 in 2007. In Spain the situation is similar, with road transportation representing $25.3 \%$ of total $\mathrm{CO}_{2}$ emissions and having increased from 50.4 million tonnes in 1990 to 97.8 in 2007. Dealing with the impact on the environment and on security of supply of the transport sector represents therefore an enormous challenge for the decision maker, given its large link with economic and social growth.

Governments and public institutions have recognized the need for action in the direction of a more sustainable (and less carbon-dependent) transportation. A clear example is the recent European Union White Paper on Transport (European Union, 2011). The general objectives claimed in the document are essentially the reduction of oil dependence and the reduction of $60 \%$ of GHGs by 2050 .

But how could governments address the transport issue in such a complex framework? 
There are many interventions a government can adopt. For instance, it can promote public transport, enhance infrastructure, subsidize more efficient technologies, or act directly on new vehicles fuel efficiencies by imposing standards. However, one of the most widely used tools for influencing private transport has been to act on the taxation level of both fuels and purchases of new cars. According to the previously cited white paper, one of the first steps to take should be to revise the current "motor fuel taxation with clear identification of the energy and $\mathrm{CO}_{2}$ component" (European Union (2011), on page 29).

However, the intervention on fuel demand through fiscal policy should be done carefully, since tax changes may affect significantly consumers' behavior and utility ${ }^{1}$. Predicting how consumers will behave is not an easy task when implementing a policy. Cross elasticities, hidden costs and rebound effects are just some examples of how difficult it is to design or modify a policy on energy and transport. Under this perspective, the need for both the data and the scientific instruments to interpret them is crucial for refining predictions and estimates of policy effects.

Partly driven by this need, the scientific literature has devoted many pages to finding a robust way to determine how agents react in their demand for transport to changes in prices and wealth. The price of fuel seems to be a main driver for its consumption, but income as well seems to influence heavily the demand for transport fuelsDel Río and Mendiluce (2010).

The two main approaches used for estimating the demand for fuel can be distinguished by the structure of the data. One approach relies on aggregate data, mostly coming from

\footnotetext{
${ }^{1}$ For a study on the redistributive effects of fuel taxes, see Asensio (2003)
} 
national accounts while the other in based on disaggregated data like household surveys ${ }^{2}$.

In Spain, the price elasticity of fuel products has been studied mainly using disaggregated models with data coming from the Spanish Statistics Institute's (INE) Family Budget Survey. Using a seven equation model, Labandeira et al. (2006) study how price changes in gasoline, electricity and other energy sources result in changes in consumption. For gasoline, findings suggest that there is no substitution effect between this product and other energy sources, mainly because of technological limits ${ }^{3}$. Romero-Jordán et al. (2010) use the same survey but focus on fuel consumption, providing a deep analysis of the state of fuel consumption in Spain. The model used in this last case is the so-called AIDS (Almost Ideal Demand System) which is adapted to fuel demand. The suggestions they give is that the low price elasticities they found for fuel are an obstacle for using gasoline tax increases for reducing oil consumption in private transport, at least in the short term. Even if both works by Labandeira et al. and Romero-Jordán et al. are using the same dataset, the differences in the results obtained are quite large. Just as an example, the resulting price elasticity obtained by Labandeira et al. is around -0.1 while in Romero-Jordán et al.'s case, the estimate of price elasticity is around -0.5 and -0.64 depending on the correction method used.

However, these two works do not differentiate between diesel and gasoline consumption (due to the impossibility to distinguish this two from the INE's dataset). This might be a

\footnotetext{
${ }^{2}$ For a broad review of past works on this topic, Goodwin (1992) and Graham and Glaister (2002) give a broad view of methods and conclusions, while the meta-analysis by Brons et al. (2008) and Espey (1998) provide a comparison of the determinants affecting the different results that can be found in the literature.

${ }^{3}$ Future developments and the diffusion of electric vehicles might change the substitution in domestic consumption between oil and electricity
} 
relevant limitation, because of the different evolution in diesel and gasoline shares (both in fuel consumption and in car fleet structure). The effects of the increasing diesel share and the related policies are the focus point of a large debate in the literature. Sterner (2007), for instance, argues that a large effect on the difference between fuel consumption in Europe and US could be explained by the higher tax levels for oil products in the European Union, and also the different treatment in taxing diesel and gasoline can play a role in this gap.

Schipper et al. (2002) (recently updated in Schipper and Fulton (2009)) show that the aggregate "real world" fuel savings coming from the increasing diesel car share are somewhat negligible or even null once compared to the potential fuel efficiency gain. Looking for the causes for this (somehow counterintuitive) phenomenon, Schipper et al. consider different possibilities. The first is that consumers are willing to purchase a diesel car instead of a gasoline one when they need to travel more. The second is that consumers decide to opt for a more comfortable (and less efficient) car taking advantage of the cheaper cost (per $\mathrm{km}$ ) of diesel technology (purchase rebound effect). The last is that consumers who have a diesel car start to drive more (and prefer it against, for example public transport) just because the cost per $\mathrm{km}$ is sufficiently low (fuel consumption rebound effect).

This provides a hint about the large, although controversial, impact that the increasing diesel-powered vehicle share has on the demand for transport and its consequences. The rebound effects are a clear example of how the shift from diesel to gasoline has non-linear effects on the consumption of both gasoline and diesel, and is one of the reasons that 
moved this paper to use aggregate instead of disaggregate data.

The model used in this paper, an adaptation of the well documented flow adjustment model presented in Houthakker and Taylor (1966), tries to include the important diesel share variable into the usual model, an attempt that was previously done by Pock (2010). The differences of the present paper with regard to the previously cited one are the data set used (Spanish instead of European), the model specification (which will be addressed in the next section), and that it studies diesel, gasoline and total fuel demand (Pock's study was restricted to gasoline demand).

In particular, the study of these three different demands for fuel (although with some limitations) should provide interesting insights on both the short and the long term reactions of consumers to changes in fuel prices and wealth.

The paper is structured in the following way. Section 2 defines the model specification, relating the classical approach to the problem to the one used here and describing briefly the data set. Section A focuses on the estimators used and section 3 will describe in detail the resulting estimates. Finally section 4 will give a brief summary of the findings and offer some concluding remarks.

\section{Model Specification}

\subsection{The classical approach and the diesel car share}

A large part of transport fuel consumption depends on fuel prices and on the wealth of the consumer (larger incomes and cheaper gasoline makes people drive more), but also 
the fleet size, composition and efficiency affect the amount of energy demanded in the transport sector.

According to previous works by Sweeney (1978) and Baltagi (1983), a general specification of the so-called "ideal demand" of fuel per car (variable $G A S^{*}$ ) is a function of the income per capita $Y / P O P$, the price of fuel $P$, the number of cars per capita $C A R / P O P$ and an efficiency factor $E$. The formulation is presented in equation (1):

$$
(G A S / C A R)^{*}=\alpha(Y / P O P)^{\beta}(P)^{\gamma}(C A R / P O P)^{\delta}(E)^{\phi} .
$$

where the fleet size per capita $C A R / P O P$ has to be considered a correction for the "per vehicle" demand, since households that own more than one vehicle do not generally drive twice as much as households that own just one. $E$ is just an indicator for the average fuel economy of the car fleet. This last parameter will not be directly considered for the estimation in this paper.

The proposed difference between the "actual" $(G A S)$ and the "ideal" $\left(G A S^{*}\right)$ demand comes from the fact that consumers need time for adapting their behavior to changes in prices and wealth. This is particularly true with regard to private transportation, since car purchases or decisions about house location are taken once every many years, a period larger than the frequency of the observations used for this work (one year).

Equation (2) shows how the relation between $G A S$ and $G A S^{*}$ is considered, according to the formulation first proposed by Houthakker and Taylor (1966), where the parameter $\theta$ represents the "speed of adjustment": 


$$
\left(\frac{(G A S / C A R)_{t}}{(G A S / C A R)_{t-1}}\right)=\left(\frac{(G A S / C A R)_{t}^{*}}{(G A S / C A R)_{t-1}}\right)^{\theta}, \text { with } 0<\theta \leq 1
$$

The "actual fuel" demand is derived in equation (3) by plugging the expression in equation (2) into (1), and then taking logarithms on both sides.

$$
\begin{aligned}
& \log (G A S / C A R)_{i, t}= \\
& \quad \theta \log (\alpha)+(1-\theta) \log (G A S / C A R)_{i, t-1}+\theta \beta \log (Y / P O P)_{i, t}+ \\
& \theta \gamma \log (P)+\theta \delta \log (C A R / P O P)_{i, t}+u_{i, t}
\end{aligned}
$$

where $u_{i, t}$ represents the usual error term.

As previously mentioned, the effects that the diesel share has on total fuel consumption should not be negligible. Pock (2010) provided a formulation that includes in the analysis of gasoline demand the number of per-capita diesel cars. In his opinion this would allow, on one hand, for not loosing the total per-capita car fleet effect on gasoline consumption and, on the other hand, capture the diesel car share effect on consumption.

In contrast with the formulation in Pock (2010), in this paper the diesel car share has been introduced as a single variable $(D S$, equal to $C A R D / C A R$, where $C A R D$ represents the quantity of diesel-powered cars circulating and $C A R$ the total number). The total fuel demand will take the form as in (4): 


$$
\begin{aligned}
& \log (G A S / C A R)_{i, t}= \\
& \quad \theta \log (\alpha)+(1-\theta) \log (G A S / C A R)_{i, t-1}+\theta \beta \log (Y / P O P)_{i, t}+ \\
& \quad \theta \gamma \log (P)_{i, t}+\theta \delta \log (C A R / P O P)_{i, t}+\theta \sigma \log (D S) \\
& \quad+u_{i, t}
\end{aligned}
$$

The formulation in (4) is the baseline that allows the estimation of gasoline, diesel and total fuel demand, as explained in section 2.2.

\subsection{Gasoline and Diesel Demand}

Although previously cited works (Baltagi, 1983; Baltagi and Griffin, 1997; Baltagi et al., 2003; Pock, 2010) used similar formulations for estimating just the gasoline consumption, avoiding to deal with the diesel consumption, here a more general representation of the demand for fuel is provided ${ }^{4}$.

In order to study the particular demands (gasoline and diesel), a modification of equation (4) is required. This is done through the introduction of new variables, which are related to the specific energy demand, car fleet, and fuel prices. $G A S G$ and $G A S D$ will be the variables associated respectively to gasoline and diesel demand. $C A R G$ and $C A R D$ will refer to gasoline- and diesel-powered-car fleets. Finally, $P G$ and $P D$, will be the final average prices for gasoline and diesel at pump. Both the demands and the prices are

\footnotetext{
${ }^{4}$ It should be noted that diesel figures include the commercial consumption, which would require a different modeling. This is one of the major reason why diesel is not considered in many studies.
} 
expressed in energy terms rather than in volume to make results comparable. Demand formulations for the total energy will be as in (4) where $C A R$ is just $(C A R G+C A R D)$, $G A S$ is $(G A S G+G A S D)$ and the price $P$ is $(P G+P D) / 2$.

Accordingly, equations (5) and (6) represent gasoline and diesel demand:

$$
\begin{aligned}
& \log (\text { GASG/CARG })_{i, t}= \\
& \quad \theta_{g} \log \left(\alpha_{g}\right)+\left(1-\theta_{g}\right) \log (G A S G / C A R G)_{i, t-1}+\theta_{g} \beta_{g} \log (Y / P O P)_{i, t}+ \\
& \quad \theta_{g} \gamma_{g} \log (P G)_{i, t}+\theta_{g} \delta_{g} \log (C A R / P O P)_{i, t}+\theta_{g} \sigma_{g} \log (D S) \\
& \quad+u_{i, t}
\end{aligned}
$$

and

$$
\begin{aligned}
& \log (G A S D / C A R D)_{i, t}= \\
& \quad \theta_{d} \log _{d}(\alpha)+\left(1-\theta_{d}\right) \log (G A S D / C A R D)_{i, t-1}+\theta_{d} \beta_{d} \log (Y / P O P)_{i, t}+ \\
& \quad \theta_{d} \gamma_{d} \log (P D)_{i, t}+\theta_{d} \delta_{d} \log (C A R / P O P)_{i, t}+\theta_{d} \sigma_{d} \log (D S) \\
& \quad+u_{i, t}
\end{aligned}
$$

It is worth noting that both the car share and diesel fleet share parameters remain untouched in the last formulations. As previously said, since the effects of the total car share (people drive less per car when there are more cars per household) should not be related to the particular technology considered. The effects of the different technologies 
are, in our model, addressed by the technology share variable $D S$ and the associated parameter $\sigma$.

\subsection{Data description}

Data cover fleet composition, fuel consumption, fuel prices and incomes for the 15 peninsular Spanish autonomous communities in Spain for the years 2000 to 2007. The main source is the National Statistics Institute (INE). Fuel consumption data comes from the National Energy Commission (CNE) while the fleet composition source is the Transit General Directorate (DGT). Regarding prices, although there are small differences among different regions, an unique nominal price for each oil product has been considered due to the lack of data.

Both fuel prices and gross domestic products are discounted for each region to year 2000 by the consumer price index.

Table 1 shows the descriptive statistics of the variables used in the model (4). It is interesting to see that while the between variability explains most of the variability of the fuel consumption, the per capita income, and the car share, the within variability is the one that explains the diesel share variability, suggesting that the way it changes is homogeneous among the regions. The price variability is not surprisingly explained by the within variability since the nominal price data are collected country-wide and later discounted by the price index. 
Table 1: Data descriptive statistics.

\begin{tabular}{lccccc}
\hline \hline & $\ln (G A S / C A R)$ & $\ln (Y / P O P)$ & $\ln (P)$ & $\ln (C A R / P O P)$ & $\ln (D S)$ \\
\hline Min & 0.974 & 0.098 & 6.426 & 0.398 & 0.237 \\
Max & 2.806 & 0.245 & 7.950 & 0.923 & 0.577 \\
\hline Mean & 1.792 & 0.167 & 7.118 & 0.653 & 0.402 \\
Overall variability & 0.500 & 0.046 & 0.500 & 0.127 & 0.115 \\
\hline Within variability & $16.9 \%$ & $24.1 \%$ & $91.5 \%$ & $24.0 \%$ & $60.3 \%$ \\
Between variability & $83.1 \%$ & $75.9 \%$ & $8.5 \%$ & $76.0 \%$ & $39.7 \%$ \\
\hline
\end{tabular}

\section{Results}

\subsection{Gasoline consumption}

In this section the results of applying the model presented in sections 2.1 and 2.2 to the data set described in 2.3 are discussed. In doing that a set of 5 homogenous estimators ${ }^{5}$ has been applied to equations (4),(5), and (6).

Table 2 shows the results of applying different estimators (described in the appendix) to equation (5), i.e. the gasoline demand. By looking thoroughly to the different estimations one can easily notice that the short term price elasticity is almost the same in every model, except the GLS-HC estimator, which produces a far lower value for the parameter. Namely, the range goes from -0.298 estimated by the corrected LSDV to -0.296 estimated by the Within, whith the GLS-HC suggesting a value of -0.165 .

Regarding the short effects of the income $(Y / P O P)$, the car share $(C A R / P O P)$, and the diesel car share $(D S)$, estimations are far more disperse, providing contrasting solutions. For instance, income has a positive effect close to 0.50 when considering the

\footnotetext{
${ }^{5}$ The estimators used are the classical OLS, a within estimator and a modified version that correct for large sample bias (LSDVc), a classical GLS estimator and a version that allows for heteroskedasticity (GLS-HC). A detailed analysis of the estimator is provided in appendix A.
} 
fixed effect estimators (Within and LSDVc), while when considering random effects (GLS and GLS-HC) and the OLS estimators, results are not significant and below 0 . The same happens when observing the estimates for the total car per capita index and the diesel car share. Estimations provided by the fixed effect estimators are both significant and of the right sign. In particular, the diesel share has a negative impact on gasoline consumption, suggesting that a growing $D S$ could indicate a shift to diesel for the high-mileage users.

Comparing these results with the ones obtained by Labandeira et al. (2006), the estimations for price elasticity are slightly lower in absolute values, with a range going from -0.058 to -0.187. By contrast, Romero-Jordán et al. (2010) found much higher values in absolute terms, around -0.46 or -0.64 depending on the correction method for infrequency of purchase. Regarding income elasticities, the model presented here provides much lower values than both examples, since in Labandeira et al. (2006), estimation are around 1.71.8, while in Romero-Jordán et al. (2010), resulting elasticities are 1.3 or 1.1, depending, as before, on the correction method adopted.

Formally, long-term-elasticities are represented by the variables in equation (1). For example, if we call $\theta_{s t}$ the estimate for the lagged variable and $\beta_{s t}$ the short term estimate for the income variable, then long-term $\beta$ is just equal to $\beta_{s t} /\left(1-\theta_{s t}\right)$. The same procedure applies to the other long term effects on independent variables. With respect to the parameter $1-\theta$ (the one associated to the lagged fuel consumption variable) and the derived long term effects, more differences between the results of the various estimators adopted emerge. Although all the estimates for this parameter are consistent with the theoretical background (equation (2)), the high values suggested by the random effect models 
(nearly 0.9 ) translate into a unrealistically high values for the long term elasticities ${ }^{6}$. The fixed effect estimators provide significant estimates that are closer to the ones presented in literature, with the long term price elasticity assuming values of -0.411 (Within) and $-0.491(\mathrm{LSDV})^{7}$.

These results do support findings by Baltagi et al. (2003) and Pock (2010) regarding the quality of the estimator used. The fixed effect estimators seem to perform well, and the relatively small population size helps in reducing biases of the within estimator, even when the correction procedure (LSDVc) is not implemented. Compared to results from Pock, the higher speed of adjustment $(\theta)$ translates into lower differences between short and long run estimates. Furthermore, the absolute values of long term elasticity seem to be higher for both price and income (namely -0.491 versus -0.408 from Pock for price and, more accentuated, 0.872 versus 0.272 for per capita income), values that are closer to Baltagi, especially regarding to the income elasticity (in this last work, the resulting long-term elasticities are -0.375 for price and 0.661 for income). These differences could arise from the different data set but, of course, the different model setting can affect, as explained later in 3.3 .

\footnotetext{
${ }^{6}$ According to the meta-analysis provided by Graham and Glaister (2002), long-term gasoline price elasticities are rarely above -2.0, and are never 4 times bigger than the associated short term elasticities (e.g. Sterner et al. (1992)), while estimations provided by GLS estimators are 10 times bigger in the long run.

${ }^{7}$ According to Espey (1998), the median for the long term price elasticity provided by the meta-analysis is -0.43 .
} 


\subsection{Diesel and total fuel consumption}

Tables 3 and 4 describe the results of diesel (equation (6)) and total fuel (equation (4)) demands. As said before, commercial fuel consumption can not be distinguished within the data, leading to an estimation bias which is difficult to be ascertain.

The resulting price effects for diesel consumption are lower than for the gasoline demand and are between -0.17 (corrected within) and -0.29 (GSL-HC). Also in this case the random effect estimators, although providing plausible estimations for the price effects, fail to produce significant results as well as a plausible speed of adjustment ${ }^{8}$ (between 0 and 1). The same happens with the total fuel demand, where both the random effect estimators fail to produce plausible results. When observing fixed effect estimates, the short term price effect is, in absolute value, above the diesel and below the gasoline estimates $(-0.22)$

Regarding the income effect, it seems that diesel is more elastic compared to gasoline, taking values of 0.875 (within) and 0.765 (corrected within). This could be caused, in part, by commercial transport, since one should expect that the commercial fleet fuel consumption is more elastic with respect to GDP. The wealth effect on total fuel demand seems to be, as with price, between the two specific fuel demands, taking values a little lower than the diesel case, namely 0.79 (within) and 0.67 (corrected within). The effects of the per capita car share and the diesel car ratio have both negative impacts on the dependent variable, although, when considering the total fuel consumption, the DS esti-

\footnotetext{
${ }^{8}$ An estimation of $(G A S / P O P)_{t-1}$ below 0 leads to a change in the sign of the other estimates when calculating the long term effects. This solution does not make sense and so those estimates are not considered.
} 
mate is not significant. This could be explained by the fact that the shift from gasoline to diesel is caused by an increasing share of low-mileage users that are in fact lowering per car diesel consumption.

Surprisingly,the long term price effect estimates for diesel and total fuel consumption are closer to the ones for gasoline. When considering the within estimator, the price effect for diesel is -0.39 (just .01 higher than the gasoline one) and for total fuel is -0.52 . The more reliable LDSVc provides values -0.54 for diesel and -0.81 for total fuel. This means that differences that do hold in the short term when the car fleet is fixed, do not hold in the longer term, when consumers can change their cars according to fuel economy or can adapt their behavior by choosing public transport or other alternatives.

\subsection{The diesel car share and estimation bias}

How does the introduction of the variable $D S$ affects the estimation? If the assumptions describing Baltagi et al. (2003) hold, one should expect the diesel share to have an nonsignificant impact on fuel demand. Pock (2010) was the first suggesting that including a measure of the diesel car share would reduce the estimation bias of the demand.

Table 3.3,shows the results obtained by the estimation of model in equation (3) (without $D S$ component) in order to compare them with the results presented by estimating equation 4 (with $D S$ component). Observing previously mentioned results 2 and 3 (gasoline and diesel estimation) it appears that the variable $D S$ has a significant negative impact on the dependent variable. The respective fixed effect estimations without the diesel-share effect (tables 5(a) and 5(b)) show a higher price effect in absolute values and 


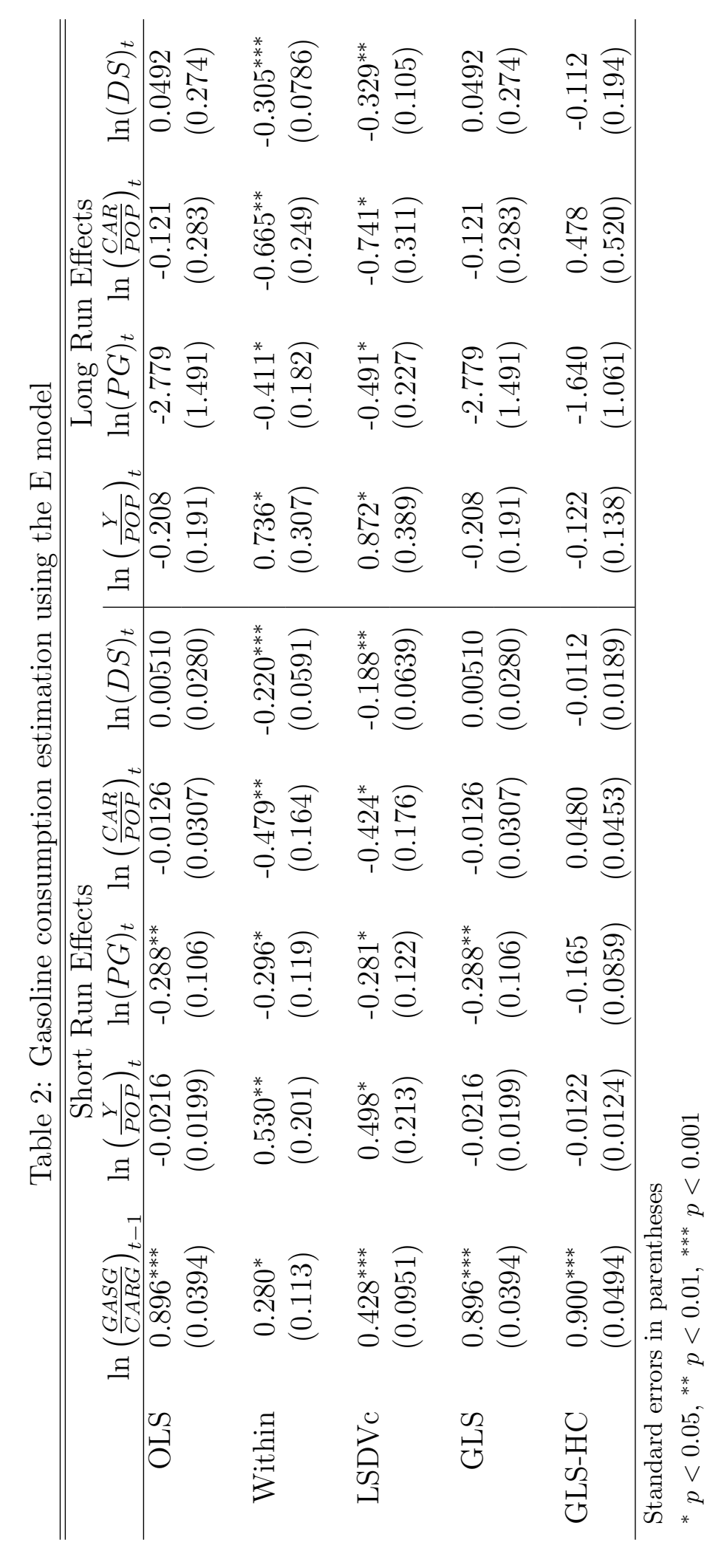




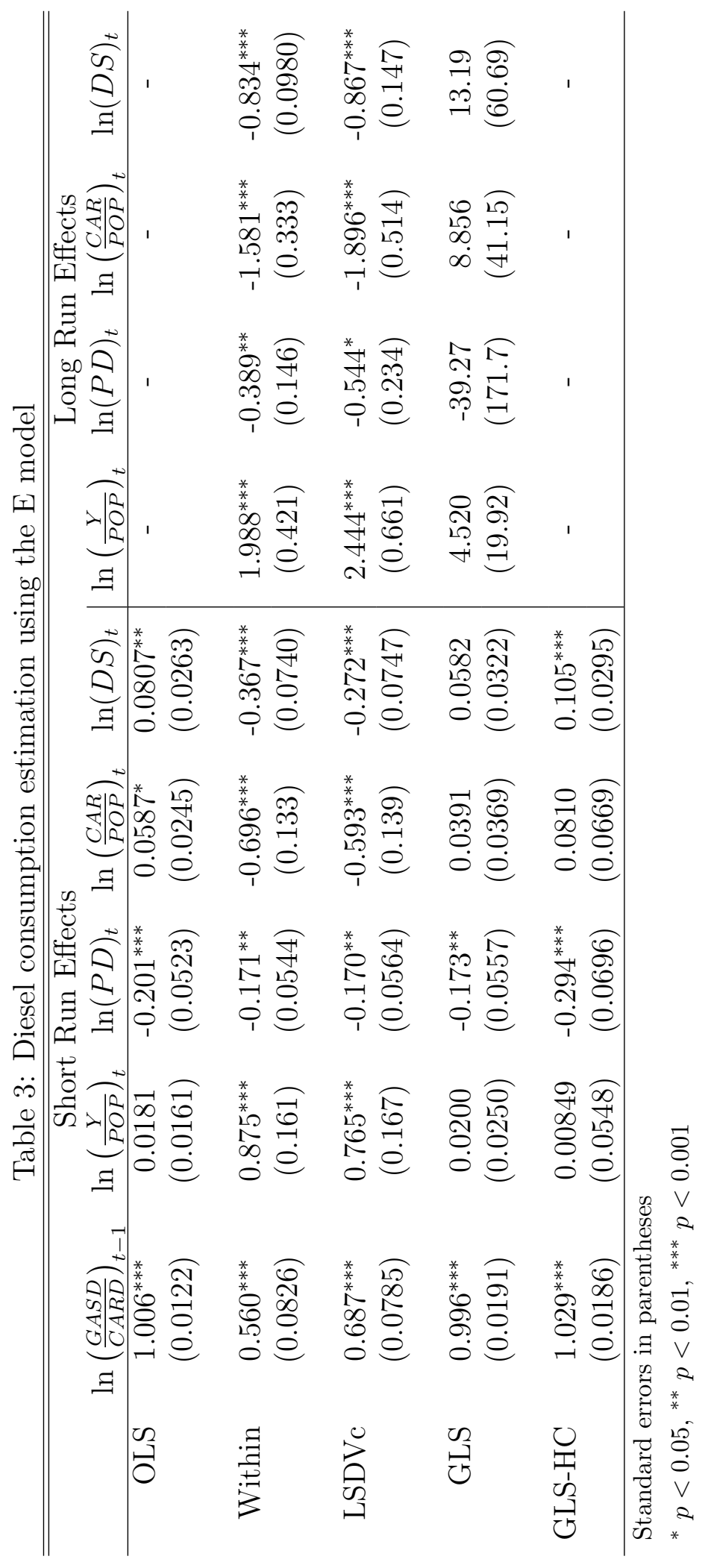




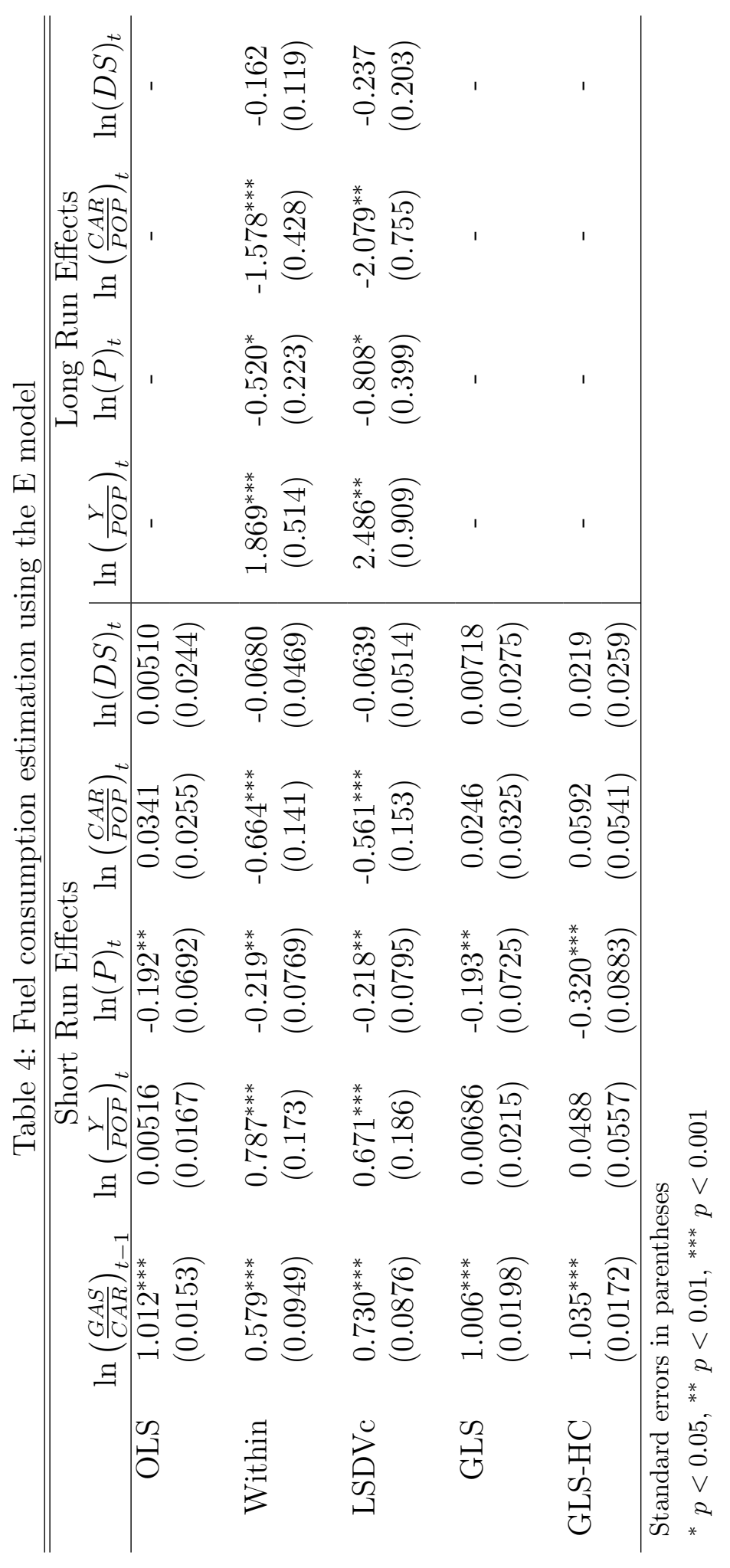


a lower effect of income on the specific fuel consumption. In the long run, the price effect on gasoline consumption estimation is also higher, providing results that are in line with Baltagi et al. (2003), around -0.7 (within) and -0.9 (LSDVc). The same does not apply to the diesel estimation (table 3) where an unrealistically high estimation of the speed of adjustment gives unlikely long term price (and income) effect estimations, with high standard error values.

Compared to results in Pock (2010), both when the $D S$ is and is not taken into account (tables 2 and 5(a) respectively), it seems that most of difference lies in the speed of adjustment term which is much lower in the case presented here. This translates in more "extreme" short and long-term values, although the long term price elasticity appears to be close enough. In addition to that, the values provided here suggest a much higher income elasticity, suggesting how the whole economy affects the gasoline consumption. This could be caused by the different data set used, but the effect of the model specification can affect the results as well.

Once comparing the total fuel demand estimation (tables 4 and 5(c)), one can see that the inclusion of the $D S$ variable has no notable impact on the estimation. The estimate for the effect of the diesel share is not significant even when considering the reliable fixed effect estimators. Excluding this variable (table 5(c)) leads to a slightly higher estimation of the price effect $(-0.25$ short term, -0.58 long term $)$ and to slightly lower income effects.

In a nutshell, the inclusion of the diesel share variable has a considerable impact when studying the particular fuel consumption (gasoline and diesel) but seems not to affect the aggregate one. These findings, on one hand, support Pock's conclusions but, on the 
other hand, suggest that the effects of this share are not that relevant once looking into the total fuel savings of an increasing diesel share. This statement corroborate the analysis by Schipper et al. (2002), according to which the large market penetration of diesel vehicles does not decrease the fuel consumption as expected.

\section{Summary and Concluding Remarks}

The increasing impact of fuel consumption and its related emissions on the environment and on energy dependence has attracted the attention of both governments and scientific community in recent years. The rising share of diesel cars through Europe during the last 20 years has also posed a number of questions about the effects it has had on fuel consumption. Only recently (Pock, 2010) tried to correct the estimation bias coming from omitting the increasing diesel share.

Adopting a similar motivation, a model that takes into account the diesel car share has been developed in this paper, allowing the estimation of gasoline, diesel and total fuel consumption. The small panel used is composed by data from 15 peninsular autonomous communities of Spain during the period 2000-2007. Five different homogeneous estimators are applied. OLS and Random Effects estimators (GLS and a version of GLS allowing for heteroscedasticity and correlation) failed to provide realistic estimates for the three fuel demands. Fixed effects estimates, on the contrary, could be considered reliable for a further analysis of the results. The within estimator and, in particular, its bias-corrected version (Bruno, 2005) gave reasonable estimates, in line with findings in Pock (2010). 
Table 5: Fuel consumption estimation using the $\mathrm{C}$ model

(a) Gasoline estimation

\begin{tabular}{rcccc|ccc}
\hline \hline & \multicolumn{9}{c}{ Short Run Effects } & \multicolumn{3}{c}{ Long Run Effects } \\
& $\ln \left(\frac{G A S G}{C A R G}\right)_{t-1}$ & $\ln \left(\frac{Y}{P O P}\right)_{t}$ & $\ln (P G)_{t}$ & $\ln \left(\frac{C A R}{P O P}\right)_{t}$ & $\ln \left(\frac{Y}{P O P}\right)_{t}$ & $\ln (P G)_{t}$ & $\ln \left(\frac{C A R}{P O P}\right)_{t}$ \\
\hline \multirow{2}{*}{ OLS } & $0.895^{* * *}$ & -0.0218 & $-0.276^{* * *}$ & -0.0129 & -0.208 & $-2.635^{*}$ & -0.123 \\
& $(0.0387)$ & $(0.0198)$ & $(0.0833)$ & $(0.0305)$ & $(0.188)$ & $(1.200)$ & $(0.279)$ \\
Within & $0.432^{* * *}$ & 0.0430 & $-0.393^{* *}$ & -0.282 & 0.0758 & $-0.692^{* *}$ & -0.497 \\
& $(0.112)$ & $(0.163)$ & $(0.124)$ & $(0.166)$ & $(0.293)$ & $(0.259)$ & $(0.320)$ \\
LSDVC & $0.587^{* * *}$ & 0.111 & $-0.384^{* *}$ & -0.262 & 0.270 & $-0.930^{*}$ & -0.634 \\
& $(0.0905)$ & $(0.158)$ & $(0.127)$ & $(0.174)$ & $(0.407)$ & $(0.373)$ & $(0.443)$ \\
GLS & $0.895^{* * *}$ & -0.0218 & $-0.276^{* * *}$ & -0.0129 & -0.208 & $-2.635^{*}$ & -0.123 \\
& $(0.0387)$ & $(0.0198)$ & $(0.0833)$ & $(0.0305)$ & $(0.188)$ & $(1.200)$ & $(0.279)$ \\
GLS-HC & $0.899^{* * *}$ & -0.0105 & -0.127 & 0.00584 & 0.186 & -0.103 & 0.0578 \\
& $(0.0498)$ & $(0.0121)$ & $(0.0844)$ & $(0.0250)$ & $(0.186)$ & $(0.131)$ & $(0.256)$ \\
\hline
\end{tabular}

Standard errors in parentheses

${ }^{*} p<0.05,{ }^{* *} p<0.01,{ }^{* * *} p<0.001$

(b) Diesel estimation

\begin{tabular}{ccccc|ccc}
\hline \hline & \multicolumn{9}{c}{ Short Run Effects } & \multicolumn{3}{c}{ Long Run Effects } \\
& $\ln \left(\frac{G A S D}{C A R D}\right)_{t-1}$ & $\ln \left(\frac{Y}{P O P}\right)_{t}$ & $\ln (P D)_{t}$ & $\ln \left(\frac{C A R}{P O P}\right)_{t}$ & $\ln \left(\frac{Y}{P O P}\right)_{t}$ & $\ln (P D)_{t}$ & $\ln \left(\frac{C A R}{P O P}\right)_{t}$ \\
\hline \multirow{5}{*}{ OLS } & $0.990^{* * *}$ & 0.0165 & $-0.0965^{*}$ & $0.0500^{*}$ & 1.693 & -9.880 & 5.123 \\
& $(0.0116)$ & $(0.0168)$ & $(0.0412)$ & $(0.0253)$ & $(2.551)$ & $(11.57)$ & $(7.135)$ \\
Within & $0.896^{* * *}$ & $0.358^{* *}$ & $-0.226^{* * *}$ & $-0.379^{* *}$ & 3.444 & -2.173 & -3.639 \\
& $(0.0534)$ & $(0.139)$ & $(0.0601)$ & $(0.131)$ & $(2.617)$ & $(1.136)$ & $(2.286)$ \\
LSDVC & $0.990^{* * *}$ & $0.469^{* * *}$ & $-0.213^{* * *}$ & $-0.391^{* *}$ & 45.05 & -20.48 & -37.60 \\
& $(0.0509)$ & $(0.136)$ & $(0.0608)$ & $(0.131)$ & $(226.2)$ & $(99.26)$ & $(185.0)$ \\
GLS & $0.977^{* * *}$ & 0.0263 & $-0.107^{*}$ & 0.0307 & 1.122 & -4.577 & 1.312 \\
& $(0.0185)$ & $(0.0273)$ & $(0.0418)$ & $(0.0402)$ & $(1.444)$ & $(3.520)$ & $(2.223)$ \\
GLS-HC & $0.996^{* * *}$ & 0.0296 & $-0.180^{*}$ & 0.0215 & 0.365 & 6.761 & 4.917 \\
& $(0.0162)$ & $(0.0667)$ & $(0.0793)$ & $(0.0592)$ & $(0.202)$ & $(30.94)$ & $(26.16)$ \\
\hline
\end{tabular}

Standard errors in parentheses

${ }^{*} p<0.05,{ }^{* *} p<0.01,{ }^{* * *} p<0.001$

(c) Total fuel estimation

\begin{tabular}{|c|c|c|c|c|c|c|c|}
\hline & \multicolumn{4}{|c|}{ Short Run Effects } & \multicolumn{3}{|c|}{ Long Run Effects } \\
\hline & $\ln \left(\frac{G A S}{C A R}\right)_{t-1}$ & $\ln \left(\frac{Y}{P O P}\right)_{t}$ & $\ln (P)_{t}$ & $\ln \left(\frac{C A R}{P O P}\right)_{t}$ & $\ln \left(\frac{Y}{P O P}\right)_{t}$ & $\ln (P)_{t}$ & $\ln \left(\frac{C A R}{P O P}\right)_{t}$ \\
\hline OLS & $\begin{array}{l}1.011^{* * *} \\
(0.0152)\end{array}$ & $\begin{array}{c}0.00502 \\
(0.0166)\end{array}$ & $\begin{array}{c}-0.183^{* * *} \\
(0.0523)\end{array}$ & $\begin{array}{c}0.0340 \\
(0.0254)\end{array}$ & - & - & - \\
\hline Within & $\begin{array}{l}0.573^{* * *} \\
(0.0954)\end{array}$ & $\begin{array}{c}0.620^{* * *} \\
(0.131)\end{array}$ & $\begin{array}{c}-0.248^{* * *} \\
(0.0748)\end{array}$ & $\begin{array}{c}-0.600^{* * *} \\
(0.135)\end{array}$ & $\begin{array}{c}1.454^{* * *} \\
(0.360)\end{array}$ & $\begin{array}{l}-0.581^{*} \\
(0.226)\end{array}$ & $\begin{array}{c}-1.406^{* * *} \\
(0.384)\end{array}$ \\
\hline LSDVc & $\begin{array}{l}0.715^{* * *} \\
(0.0891)\end{array}$ & $\begin{array}{c}0.525^{* * *} \\
(0.136)\end{array}$ & $\begin{array}{l}-0.260^{* *} 22 \\
(0.0802)\end{array}$ & $\begin{array}{c}-0.501^{* * *} \\
(0.149)\end{array}$ & $\begin{array}{l}1.842^{* *} \\
(0.616)\end{array}$ & $\begin{array}{l}-0.910^{*} \\
(0.411)\end{array}$ & $\begin{array}{c}-1.759^{* *} \\
(0.649)\end{array}$ \\
\hline GLS & $\begin{array}{l}1.007^{* * *} \\
(0.0187)\end{array}$ & $\begin{array}{l}0.00646 \\
(0.0204)\end{array}$ & $\begin{array}{c}-0.181^{* * *} \\
(0.0527)\end{array}$ & $\begin{array}{c}0.0271 \\
(0.0308)\end{array}$ & - & - & - \\
\hline GLS-HC & $\begin{array}{l}1.033^{* * *} \\
(0.0172)\end{array}$ & $\begin{array}{c}0.0404 \\
(0.0546)\end{array}$ & $\begin{array}{c}-0.276^{* * *} \\
(0.0694)\end{array}$ & $\begin{array}{c}0.0592 \\
(0.0534)\end{array}$ & - & - & \\
\hline
\end{tabular}

Standard errors in parentheses

${ }^{*} p<0.05,{ }^{* *} p<0.01,{ }^{* * *} p<0.001$ 
The qualitative results of the estimation are in line with both the predictions of economic theory and the literature results like Baltagi and Griffin (1997), Baltagi et al. (2003) and Pock (2010), showing positive income elasticity, negative price elasticity and negative effects of the per capita car ratio. The quantitative results differ from Pock's in that short and long run elasticities are not so different (consumers have a higher speed of adjustment). In the long run the price elasticity for gasoline is quite similar while the income elasticity is much higher in the results presented here. This can depend on the different data set used, but can depend also on the slightly different specification of the model.

The correction of a variable summarizing the diesel car share when estimating the three different fuel demands (gasoline, gasoil and total fuel) seems to be affecting two of them (the "specific ones"). This can be interpreted as the bias affects just the specific fuel consumption, but once the overall consumption is considered, the effect of the technology should be captured directly by the economy-setting variables, such as price and income.

From the policy maker's perspective, the mere quantitative findings should suggest, once again, how powerful fiscal measures have been and can be in the future. However, the increasing shift to diesel, which helped to reduce overall fuel consumption, has not produced clear effects on GHG emissions ${ }^{9}$. According to the results presented, a higher ratio of diesel cars are responsible for lower diesel and gasoline demands only when considering the two demands separately ${ }^{10}$.

As Sterner (2007) suggest, a reduction of the demand should be done through a com-

\footnotetext{
${ }^{9}$ as showed in Schipper et al. (2002).

${ }^{10}$ As an example, according to the analysis, an increase of $20 \%$ in the taxation of fuels would lead to an increase of $8-9 \%$ in its final price. This would lead to a decrease of the demand of less than $2 \%$ in the short term but $6.5-7 \%$ in the long run.
} 
mitment to a progressive but continuous taxation increase, and followed by an improvement of the public transportation network, if the objective of the government is to improve the sustainability in the whole transportation system. Moreover, given the recent developments in new gasoline car efficiency and the reduced gain in $\mathrm{CO}_{2}$ emissions coming from new diesel cars, the tax differences in taxation should be reduced as well between the two fuel types. 


\section{A Estimators}

There is a large literature that focuses on the quality of estimators in fuel demand models among other applications. In a setting similar to the one used here, Baltagi and Griffin (1997) compare the performance of 11 homogeneous and 13 heterogeneous estimators using the gasoline consumption data for a 30-year-long panel of OECD countries. In this setting they evaluate the performance of the estimators by using three different metrics. These metrics are the theoretical (a priori) suitability, the plausability of price and income elasticities, and finally the forecast performance of the different estimators, with the help of out-of-sample data. Evidence shows that homogeneous estimators outperform heterogeneous ones in both forecast trials and plausability, contrasting with the theoretical prediction.

These results are confirmed in a later paper by Baltagi et al. (2003) using a data set from 21 french regions, with the evidence leading to not consider heterogeneous estimators in this work. Problems emerge as well when considering endogenous estimators like Instrumental Variables or Generalized Methods of Moments. Here, the difficulty of choosing the correct instruments for the variables often lead (as shown in Baltagi and Griffin (1997)) to poor results.

The estimators taken into consideration for this analysis will be then the classical OLS model (just for a comparison purposes), a (fixed effects) Within estimator, a (random effects) feasible GLS, applying the Swamy and Arora process (Swamy and Arora, 1972). A second feasible GLS is then considered, where a richer error component term 
should provide more reliable results. In this latter case, a feasible GLS that allows for heteroscedasticity with autoregressive AR(1) components will be applied.

Finally, following Pock (2010), we include a corrected LSVD estimator. The well known bias (described in Nickell (1981)) is known for affecting results using within estimator for large $N^{11}$.

Summarizing, even if the set of estimators is smaller than the one presented in Baltagi and Griffin (1997) Baltagi et al. (2003) and Pock (2010), the previously mentioned papers should provide a sufficient evidence for considering the set of estimators satisfying for the analysis. Results of the estimation and the following discussion is provided in the main text.

${ }^{11}$ The procedure adopted and the relative STATA code comes from the one presented in Bruno (2005). 


\section{References}

Asensio, J. (2003). Petrol expenditure and redistributive effects of its taxation in Spain. ... Research Part A: Policy and Practice.

Baltagi, B. H. (1983). Gasoline demand in the OECD An application of pooling and testing procedures. European Economic Review, 22(2):117-137.

Baltagi, B. H., Bresson, G., Griffin, J. M., and Pirotte, A. (2003). Homogeneous, heterogeneous or shrinkage estimators? Some empirical evidence from French regional gasoline consumption. Empirical Economics, 28(4):795-811.

Baltagi, B. H. and Griffin, J. M. (1997). Pooled estimators vs. their heterogeneous counterparts in the context of dynamic demand for gasoline. Journal of Econometrics, $77(2): 303-327$.

Brons, M., Nijkamp, P., Pels, E., and Rietvield, P. (2008). A meta-analysis of the price elasticity of gasoline demand. A SUR approach. Energy Economics, 30(5):2105-2122.

Bruno, G. (2005). Approximating the bias of the LSDV estimator for dynamic unbalanced panel data models. Economics Letters, 87(3):361-366.

Del Río, P. and Mendiluce, M. (2010). Energía y transporte. Cuadernos Económicos de ICE, (79):213-236.

Espey, M. (1998). Gasoline demand revisited: an international meta-analysis of elasticities. Energy Economics, 20(3):273-295. 
European Commision (2010). EU Energy and Transport in figures. Technical report, Brussels.

European Union (2011). Roadmap to a Single European Transport Area Towards a competitive and resource efficient transport system.

Goodwin, P. B. (1992). A Review of New Demand Elasticities with Special Reference to Short and Long Run Effects of Price Changes. Journal of Transport Economics and Policy, 26(2):155 - 169 .

Graham, D. J. and Glaister, S. (2002). The demand for automobile fuel: a survey of elasticities. Journal of Transport Economics and Policy, 36(1):1-25.

Houthakker, H. S. and Taylor, L. D. (1966). Consumer demand in the United States, 1929-1970: Analyses and projections. Harvard university press.

Labandeira, X., Labeaga, J. M., and Rodríguez, M. (2006). A Residential Energy Demand System for Spain. The Energy Journal, 27(2):87-112.

Nickell, S. (1981). Biases in dynamic models with fixed effects. Econometrica, 49(6):14171426.

Pock, M. (2010). Gasoline demand in Europe: New insights. Energy Economics, 32(1):5462.

Romero-Jordán, D., del Río, P., Jorge-García, M., and Burguillo, M. (2010). Price and 
income elasticities of demand for passenger transport fuels in Spain. Implications for public policies. Energy Policy, 38(8):3898-3909.

Schipper, L. and Fulton, L. (2009). Disappointed by Diesel? Impact of Shift to Diesels in Europe Through 2006. Transportation research record, (2139):1-10.

Schipper, L., Marie-Lilliu, C., and Fulton, L. (2002). Diesels in Europe: Analysis of Characteristics, Usage Patterns, Energy Savings and Co Emission Implications. Journal of Transport Economics and Policy, 36(2):305-340.

Sterner, T. (2007). Fuel taxes: An important instrument for climate policy. Energy Policy, 35(6):3194-3202.

Sterner, T., Dahl, C., and Franzén, M. (1992). Gasoline Tax Policy, Carbon Emissions and the Global Environment. Journal of Transport Economics and Policy, 26(2).

Swamy, P. and Arora, S. (1972). The exact finite sample properties of the estimators of coefficients in the error components regression models. Econometrica, pages 261-275.

Sweeney, J. (1978). The demand for gasoline in the United States: a vintage capital model. In Workshop on energy and supply and demand, International Energy Agency, Paris, pages 240-277. 